\author{
N.A. Kachanovsky \\ Institute of Mathematics of NASU, Kyiv, Ukraine

\section{BOUNDED OPERATORS OF STOCHASTIC DIFFERENTIATION ON SPACES OF NONREGULAR GENERALIZED FUNCTIONS IN THE LÉVY WHITE NOISE ANALYSIS}

Background. Operators of stochastic differentiation play an important role in the Gaussian white noise analysis. In particular, they can be used in order to study properties of the extended stochastic integral and of solutions of normally ordered stochastic equations. Although the Gaussian analysis is a developed theory with numerous applications, in problems of mathematics not only Gaussian random processes arise. In particular, an important role in modern researches belongs to Lévy processes. So, it is necessary to develop a Lévy analysis, including the theory of operators of stochastic differentiation.

Objective. During recent years the operators of stochastic differentiation were introduced and studied, in particular, on spaces of regular test and generalized functions and on spaces of nonregular test functions of the Lévy analysis. In this paper, we make the next step: introduce and study such operators on spaces of nonregular generalized functions. Methods. We use, in particular, the theory of Hilbert equipments and Lytvynov's generalization of the chaotic representation property.

Results. The main result is a theorem about properties of operators of stochastic differentiation.

Conclusions. The operators of stochastic differentiation are considered on the spaces of nonregular generalized functions of the Lévy white noise analysis. This can be interpreted as a contribution in a further development of the Lévy analysis. Applications of the introduced operators are quite analogous to the applications of the corresponding operators in the Gaussian analysis.

Keywords: operator of stochastic differentiation; extended stochastic integral; Hida stochastic derivative; Lévy process.

\section{Introduction}

Denote $R_{+}:=[0,+\infty)$. Let $L=\left(L_{t}\right)_{t \in R_{+}}$be a Lévy process, i.e., a random process on $R_{+}$with stationary independent increments and such that $L_{0}=0$ (see, e.g., [1] for details), without Gaussian part and drift. In [2] the extended Skorohod stochastic integral with respect to $L$ and the corresponding Hida stochastic derivative on the space of square integrable random variables $\left(L^{2}\right)$ were constructed in terms of Lytvynov's generalization of the chaotic representation property (CRP) [3], some properties of these operators were established; and it was shown that the above-mentioned integral coincides with the well-known extended stochastic integral with respect to a Lévy process, constructed in terms of Itô's generalization of the CRP [4] (see, e.g., [5, 6]). In [7, 8] the stochastic integral and derivative were extended to spaces of test and generalized functions that belong to riggings of $\left(L^{2}\right)$, this gives a possibility to extend an area of their possible applications. Together with the mentioned operators, it is natural to introduce and to study so-called operators of stochastic differentiation in the Lévy white noise analysis, by analogy with the Gaussian analysis $[9,10]$. Such operators are closely related with the extended sto- chastic integral with respect to a Lévy process and with the corresponding Hida stochastic derivative and, by analogy with the "classical case", can be used, in particular, in order to study properties of the extended stochastic integral and properties of solutions of so-called normally ordered stochastic equations. In $[11,12]$ the operators of stochastic differentiation on spaces belonging to a so-called regular parametrized rigging of $\left(L^{2}\right)$ [7] were introduced and studied. But, in connection with some problems of the stochastic analysis, sometimes it can be necessary to consider another, a so-called nonregular rigging of $\left(L^{2}\right)$ [7] and various operators on spaces (of nonregular test and generalized functions) belonging to this rigging. In [13] operators of stochastic differentiation were introduced and studied on the spaces of nonregular test functions of the Lévy white noise analysis. In particular, it was shown that these operators are the restrictions to the above-mentioned spaces of the corresponding operators on $\left(L^{2}\right)$. The next natural step consists in introduction and study of operators of stochastic differentiation on the spaces of nonregular generalized functions. But, unfortunately, the operators of stochastic differentiation on $\left(L^{2}\right)$ (in the same way as the Hida stochastic derivative) 
cannot be naturally continued to the abovementioned spaces. Nevertheless, one can introduce on these spaces linear operators with properties quite analogous to properties of the operators of stochastic differentiation. These linear operators will be called the operators of stochastic differentiation on the spaces of nonregular generalized functions. In the present paper we introduce these operators and establish some their properties.

\section{Problem definition}

The aim of this paper is to introduce the operators of stochastic differentiation on the spaces of nonregular generalized functions of the Lévy white noise analysis; and to establish some properties of these operators.

\section{Preliminaries}

In this paper we deal with a real-valued locally square integrable Lévy process $L$ on $R_{+}$ without Gaussian part and drift. As is well known, the characteristic function of such a process is

$$
E\left[e^{i u L_{t}}\right]=\exp \left[t \int_{R}\left(e^{i u x}-1-i u x\right) v(d x)\right],
$$

where $v$ is the Lévy measure of $L, E$ denotes the expectation. We assume that $v$ is a Radon measure whose support contains an infinite number of points, $v(\{0\})=0$, there exists $\varepsilon>0$ such that

$\int_{R} x^{2} e^{\varepsilon|x|} v(d x)<\infty$, and $\int_{R} x^{2} v(d x)=1$.

Let us define a measure of the white noise of $L$. Let $D$ denote the set of all real-valued infnitedifferentiable functions on $R_{+}$with compact supports. As is well known, $D$ can be endowed by the projective limit topology generated by some Sobolev spaces (more details are given below, a detailed presentation is given in, e.g., [14]). Let $D^{\prime}$ be the set of linear continuous functionals on $D$. For $\omega \in D^{\prime}$ and $\varphi \in D$ denote $\langle\omega, \varphi\rangle:=\omega(\varphi)$; note that one can understand $\langle\cdot, \cdot\rangle$ as the dual pairing generated by the scalar product in the space $L^{2}\left(R_{+}\right)$of square integrable with respect to the Lebesgue measure real-valued functions on $R_{+}$. The notation $\langle\cdot, \cdot\rangle$ will be preserved for dual pairings in tensor powers of spaces.

Definition ([3]). A probability measure $\mu$ on $\left(D^{\prime}, C\left(D^{\prime}\right)\right)$, where $C$ denotes the cylindrical $\sigma$ algebra, with the Fourier transform

$$
\begin{gathered}
\int_{D^{\prime}} e^{i\langle\omega, \varphi\rangle} \mu(d \omega) \\
=\exp \left[\int_{R_{+} \times R}\left(e^{i \varphi(u) x}-1-i \varphi(u) x\right) d u v(d x)\right], \varphi \in D,
\end{gathered}
$$

is called the Lévy white noise measure.

Denote $\left(L^{2}\right):=L^{2}\left(D^{\prime}, C\left(D^{\prime}\right), \mu\right)$ the space of real-valued square integrable with respect to $\mu$ functions on $D^{\prime}$; let also $H:=L^{2}\left(R_{+}\right)$. Let $f \in H$ and a sequence $\left(\varphi_{k} \in D\right)_{k \in N}$ converge to $f$ in $H$ as $k \rightarrow \infty$. One can show $[2,3,5,6]$ that $\langle\circ, f\rangle:=$ $=\left(L^{2}\right)-\lim _{k \rightarrow \infty}\left\langle 0, \varphi_{k}\right\rangle$ is well defined as an element of $\left(L^{2}\right)$. Let us consider $\left\langle\circ, 1_{[0, t)}\right\rangle \in\left(L^{2}\right), t \in R_{+}$(here and below $1_{A}$ denotes the indicator of a set $A$ ). It follows from (1) and (2) that $\left(\left\langle o, 1_{[0, t)}\right\rangle\right)_{t \in R_{+}}$can be identified with a Lévy process $L$.

Consider Lytvynov's generalization of the CRP (see [3] for details). Denote by $\otimes$ the symmetric tensor product. For $m \in Z_{+}:=N \cup\{0\}$ set

$$
P_{m}:=\left\{\varphi(\omega)=\sum_{k=0}^{l}\left\langle\omega^{\otimes k}, \varphi^{(k)}\right\rangle \mid \omega \in D^{\prime}, \varphi^{(k)} \in D^{\otimes k}, l \leq m\right\} .
$$

Denote by $\bar{P}_{m}$ the closure of $P_{m}$ in $\left(L^{2}\right)$. Let for $m \in N \quad \mathrm{P}_{m}$ be defined from the condition $\bar{P}_{m}=$ $=\mathrm{P}_{m} \oplus \bar{P}_{m-1}, \mathrm{P}_{0}:=\bar{P}_{0}$. Let $f^{(m)} \in D^{\widehat{\otimes} m}, m \in Z_{+}$. Denote by : $\left\langle 0^{\otimes m}, f^{(m)}\right\rangle$ : the orthogonal projection of a monomial $\left\langle 0^{\otimes m}, f^{(m)}\right\rangle$ onto $\mathrm{P}_{m}$. Let us introduce scalar products $(\cdot, \cdot)_{\mathrm{ext}}$ on $D^{\otimes m}, m \in Z_{+}\left(D^{\otimes 0}:=R\right)$, by setting for $f^{(m)}, g^{(m)} \in D^{\widehat{\otimes} m}$

$$
\begin{gathered}
\left(f^{(m)}, g^{(m)}\right)_{\mathrm{ext}} \\
:=\frac{1}{m !} \int_{D^{\prime}}:\left\langle\omega^{\otimes m}, f^{(m)}\right\rangle::\left\langle\omega^{\otimes m}, g^{(m)}\right\rangle: \mu(d \omega),
\end{gathered}
$$

and let $|\cdot|_{\text {ext }}$ be the corresponding norms. Denote by $H_{\mathrm{ext}}^{(m)}, m \in Z_{+}$, the completions of $D^{\otimes m}$ with respect to the norms $|\cdot|_{\text {ext }}$. For $F^{(m)} \in H_{\mathrm{ext}}^{(m)}$ we define a Wick monomial $:\left\langle 0^{\otimes m}, F^{(m)}\right\rangle: \stackrel{d e f}{=}\left(L^{2}\right)-$ $-\lim _{k \rightarrow \infty}:\left\langle 0^{\otimes m}, f_{k}^{(m)}\right\rangle:$, here for each $k \in N$ $f_{k}^{(m)} \in D^{\widehat{\otimes} m}$, and $f_{k}^{(m)} \rightarrow F^{(m)}$ as $k \rightarrow \infty$ in $H_{\mathrm{ext}}^{(m)}$ (well-posedness of this definition can be proved by the method of "mixed sequences"). One can show [3] that $F \in\left(L^{2}\right)$ if and only if there is a unique se- 
quence of kernels $F^{(m)} \in H_{\mathrm{ext}}^{(m)}, \quad m \in Z_{+}$, such that

$$
F=\sum_{m=0}^{\infty}:\left\langle 0^{\otimes m}, F^{(m)}\right\rangle:
$$

with

$$
E|F|^{2}=\|F\|_{\left(L^{2}\right)}^{2}=\int_{D^{\prime}}|F(\omega)|^{2} \mu(d \omega)=\sum_{m=0}^{\infty} m !\left|F^{(m)}\right|_{\text {ext }}^{2}<\infty .
$$

Note that $H_{\mathrm{ext}}^{(1)}=H$ and for $m \in N \backslash\{1\}$ one can identify $H^{\widehat{\otimes} m}$ with a proper subspace of $H_{\mathrm{ext}}^{(m)}$ that consists of "vanishing on diagonals" elements $[2,3]$. In this sense the space $H_{\mathrm{ext}}^{(m)}$ is an extension of $H^{\otimes m}$.

Denote by $T$ the set of indexes $\tau=\left(\tau_{1}, \tau_{2}\right)$, where $\tau_{1} \in N, \tau_{2}: R_{+} \rightarrow[1,+\infty)$ is an infinite differentiable function. Let $H_{\tau}, \tau \in T$, be the Sobolev space on $R_{+}$of order $\tau_{1}$ weighted by the function $\tau_{2}$ (e.g., [14]). It is well known that $D=p r \lim _{\tau \in T} H_{\tau}$ (moreover, $D^{\widehat{\otimes} m}=p r \lim _{\tau \in T} H_{\tau}^{\widehat{\otimes} m}$, $m \in N$ ), and for each $\tau \in T H_{\tau}$ is densely and continuously embedded into $H$. Therefore one can consider a chain

$$
D^{\prime} \supset H_{-\tau} \supset H \supset H_{\tau} \supset D,
$$

where $H_{-\tau}, \tau \in T$, are the spaces dual of $H_{\tau}$ with respect to $H$. Note that by the Schwartz theorem (e.g., [14]) $D^{\prime}=\bigcup_{\tau \in T} H_{-\tau}$.

By analogy with [15] (see also [3]) one can show that the measure $\mu$ is concentrated on $H_{-\tilde{\tau}}$ with some $\tilde{\tau} \in T$, i.e., $\mu\left(H_{-\tilde{\tau}}\right)=1$. So, excepting from $T$ some indexes, we will assume, in what follows, that for each $\tau \in T \mu\left(H_{-\tau}\right)=1$. Further, denote the norms in $H_{\tau}$ and its tensor powers by $|\cdot|_{\tau}$. It is shown in [7] that, again excepting from $T$ some indexes, we obtain the next statement.

Proposition. For each $\tau \in T$ and for each $m \in N$ the space $H_{\tau}^{\otimes m}$ is densely and continuously embedded into the space $H_{\mathrm{ext}}^{(m)}$, and there exists $c(\tau)>0$ such that for all $f^{(m)} \in H_{\tau}^{\widehat{\otimes} m}$ we have $\left|f^{(m)}\right|_{\mathrm{ext}}^{2} \leq m ! c(\tau)^{m}\left|f^{(m)}\right|_{\tau}^{2}$.

Denote

$$
P_{W}:=\left\{f=\sum_{m=0}^{N_{f}}:\left\langle 0^{\otimes m}, f^{(m)}\right\rangle:, f^{(m)} \in D^{\bar{\otimes} m}, N_{f} \in Z_{+}\right\} \subset\left(L^{2}\right) \text {. }
$$

Accept on default $q \in Z_{+}, \tau \in T$; set $H_{\tau}^{\otimes 0}:=R$; and define scalar products $(\cdot,)_{\tau, q}$ on $P_{W}$ by setting for $f, g \in P_{W}$

$$
(f, g)_{\tau, q}:=\sum_{m=0}^{\min \left(N_{f}, N_{g}\right)}(m !)^{2} 2^{q m}\left(f^{(m)}, g^{(m)}\right)_{H_{\tau} \overline{\otimes m}}
$$

(see [13] for details). Let $\|\cdot\|_{\tau, q}$ be the corresponding norms. Now we define Kondratiev spaces of nonregular test functions $\left(H_{\tau}\right)_{q}$ as completions of $P_{W}$ with respect to the norms $\|\cdot\|_{\tau, q}$. As is easy to see, $f \in\left(H_{\tau}\right)_{q}$ if and only if $f$ can be presented in the form

$$
f=\sum_{m=0}^{\infty}:\left\langle 0^{\otimes m}, f^{(m)}\right\rangle:, f^{(m)} \in H_{\tau}^{\otimes m},
$$

with $\|f\|_{\left(H_{\tau}\right)_{q}}^{2}=\sum_{m=0}^{\infty}(m !)^{2} 2^{q m}\left|f^{(m)}\right|_{\tau}^{2}<\infty$.

Further, it is proved in [7] that for each $\tau \in T$ there exists $q_{0}(\tau) \in Z_{+}$such that for each $q \in Z_{+}, q \geq q_{0}(\tau)$, the space $\left(H_{\tau}\right)_{q}$ is densely and continuously embedded into $\left(L^{2}\right)$. In view of this statement for $\tau \in T$ and $q \geq q_{0}(\tau)$ one can consider a chain

$$
\left(H_{-\tau}\right)_{-q} \supset\left(L^{2}\right) \supset\left(H_{\tau}\right)_{q},
$$

where $\left(H_{-\tau}\right)_{-q}$ is the space dual of $\left(H_{\tau}\right)_{q}$ with respect to $\left(L^{2}\right)$. Chain (4) is called a nonregular rigging of the space $\left(L^{2}\right)$. The negative spaces $\left(H_{-\tau}\right)_{-q}$ of such chains (with various $\tau$ and $q$ ) are called Kondratiev spaces of nonregular generalized functions.

Now let us describe natural orthogonal bases in the spaces $\left(H_{-\tau}\right)_{-q}$. In view of the Proposition formulated above let us consider chains

$$
D^{\prime(m)} \supset H_{-\tau}^{(m)} \supset H_{\mathrm{ext}}^{(m)} \supset H_{\tau}^{\otimes m} \supset D^{\bar{\otimes} m}, m \in N
$$

(for $m=0$ set $D^{\prime(0)}=H_{-\tau}^{(0)}=H_{\mathrm{ext}}^{(0)}=H_{\tau}^{\widehat{\otimes} 0}=D^{\widehat{\otimes} 0}:=R$ ), where $H_{-\tau}^{(m)}$ and $D^{\prime(m)}=\bigcup_{\tau \in T} H_{-\tau}^{(m)}$ are the spaces dual of $H_{\tau}^{\otimes m}$ and $D^{\widehat{\otimes} m}$ with respect to $H_{\mathrm{ext}}^{(m)}$.

Proposition ([7]). There exists a system of generalized functions

$$
\left\{:\left\langle 0^{\otimes m}, F_{\mathrm{ext}}^{(m)}\right\rangle: \in\left(H_{-\tau}\right)_{-q} \mid F_{\mathrm{ext}}^{(m)} \in H_{-\tau}^{(m)}, m \in Z_{+}\right\}
$$

such that 
1) for $F_{\mathrm{ext}}^{(m)} \in H_{\mathrm{ext}}^{(m)} \subset H_{-\tau}^{(m)}:\left\langle\mathrm{o}^{\otimes m}, F_{\mathrm{ext}}^{(m)}\right\rangle$ : is a Wick monomial;

2) any generalized function $F \in\left(H_{-\tau}\right)_{-q}$ can be presented as a formal series

$$
F=\sum_{m=0}^{\infty}:\left\langle 0^{\otimes m}, F_{\mathrm{ext}}^{(m)}\right\rangle:, F_{\mathrm{ext}}^{(m)} \in H_{-\tau}^{(m)},
$$

that converges in $\left(H_{-\tau}\right)_{-q}$, i.e.,

$$
\|F\|_{\left(H_{-\tau}\right)_{-q}}^{2}=\sum_{m=0}^{\infty} 2^{-q m}\left|F_{\mathrm{ext}}^{(m)}\right|_{H_{-\tau}^{(m)}}^{2}<\infty ;
$$

and any formal series (6) with finite norm (7) is a generalized function from $\left(H_{-\tau}\right)_{-q}$;

3) the dual pairing between $F \in\left(H_{-\tau}\right)_{-q}$ and $f \in\left(H_{\tau}\right)_{q}$ that is generated by the scalar product in $\left(L^{2}\right)$, has the form

$$
\langle\langle F, f\rangle\rangle_{\left(L^{2}\right)}=\sum_{m=0}^{\infty} m !\left\langle F_{\mathrm{ext}}^{(m)}, f^{(m)}\right\rangle_{\mathrm{ext}},
$$

where $F_{\text {ext }}^{(m)} \in H_{-\tau}^{(m)}$ and $f^{(m)} \in H_{\tau}^{\otimes m}$ are the kernels from decompositions (6) and (3) for $F$ and $f$ respectively, $\langle\cdot, \cdot\rangle_{\mathrm{ext}}$ denotes the dual pairings between elements of negative and positive spaces from chains (5), these pairings are generated by the scalar products in $H_{\mathrm{ext}}^{(m)}, m \in Z_{+}$.

Following [13], we recall now a notion of the extended stochastic integral on $\left(H_{-\tau}\right)_{-q} \otimes H_{-\tau}$. First we note that there exists a system of orthogonal in $\left(H_{-\tau}\right)_{-q} \otimes H_{-\tau}$ generalized functions $\left\{:\left\langle 0^{\otimes m}, F_{\mathrm{ext},}^{(m)}\right\rangle: \in\left(H_{-\tau}\right)_{-q} \otimes H_{-\tau} \mid F_{\mathrm{ext}, .}^{(m)} \in H_{-\tau}^{(m)} \otimes H_{-\tau}\right.$, $\left.m \in Z_{+}\right\}$such that any $F \in\left(H_{-\tau}\right)_{-q} \otimes H_{-\tau}$ can be presented as a convergent in this space series

$$
F(\cdot)=\sum_{m=0}^{\infty}:\left\langle 0^{\otimes m}, F_{\mathrm{ext}, .}^{(m)}\right\rangle:, F_{\mathrm{ext}, .}^{(m)} \in H_{-\tau}^{(m)} \otimes H_{-\tau},
$$

with $\|F\|_{\left(H_{-\tau}\right)_{-q} \otimes H_{-\tau}}^{2}=\sum_{m=0}^{\infty} 2^{-q m}\left|F_{\mathrm{ext},}^{(m)} \cdot\right|_{H_{-\tau}^{(m)} \otimes H_{-\tau}}^{2}<\infty$.

Consider a family of chains

$$
D^{, \otimes m} \supset H_{-\tau}^{\otimes m} \supset H^{\widehat{\otimes} m} \supset H_{\tau}^{\otimes m} \supset D^{\widehat{\otimes} m}, m \in N
$$

(as is well known (e.g., [14]), $H_{-\tau}^{\otimes m}$ and $D^{\prime \otimes m}$ $=\bigcup_{\tau \in T} H_{-\tau}^{\otimes m}$ are the spaces dual of $H_{\tau}^{\otimes} m$ and $D^{\otimes m}$ with respect to $H^{\otimes m}$; for $m=0$ all spaces from (10) are equal to $R$ by definition). Since the spaces of test functions in chains (10) and (5) co- incide, there exists a family of natural isomorphisms $U_{m}: D^{\prime(m)} \rightarrow D^{\prime^{\otimes m}}$ such that for all $F_{\mathrm{ext}}^{(m)} \in D^{\prime(m)}$ and $f^{(m)} \in D^{\otimes} \otimes\left\langle F_{\mathrm{ext}}^{(m)}, f^{(m)}\right\rangle_{\mathrm{ext}}=\left\langle U_{m} F_{\mathrm{ext}}^{(m)}, f^{(m)}\right\rangle$. It is easy to see that the restrictions of $U_{m}$ to $H_{-\tau}^{(m)}$ are isometric isomorphisms between the spaces $H_{-\tau}^{(m)}$ and $H_{-\tau}^{\otimes m}$. Now we introduce an extended stochastic integral $\int \circ(u) \hat{d} L_{u}:\left(H_{-\tau}\right)_{-q} \otimes H_{-\tau} \rightarrow\left(H_{-\tau}\right)_{-q}$ as a linear continuous operator that is defined for $F \in\left(H_{-\tau}\right)_{-q} \otimes H_{-\tau}$ of form (9) as

$$
\int F(u) \widehat{d} L_{u}:=\sum_{m=0}^{\infty}:\left\langle 0^{\otimes m+1}, \widehat{F}_{\mathrm{ext}}^{(m)}\right\rangle:,
$$

here $\hat{F}_{\mathrm{ext}}^{(m)}:=U_{m+1}^{-1}\left\{\operatorname{Pr}\left[\left(U_{m} \otimes 1\right) F_{\mathrm{ext},}^{(m)}\right]\right\} \in H_{-\tau}^{(m+1)}, \operatorname{Pr}$ is the orthoprojector acting for each $m \in Z_{+}$from $H_{-\tau}^{\widehat{\otimes} m} \otimes H_{-\tau}$ to $H_{-\tau}^{\widehat{\otimes} m+1}$ (the symmetrization operator), 1 is the identity operator. It is shown in [13] that this integral is an extension of the extended Skorohod stochastic integral with respect to a Lévy process $L$.

Unfortunately, the extended stochastic integral with respect to a Lévy process cannot be naturally restricted to the spaces of nonregular test functions. More precisely, for $f \in\left(H_{\tau}\right)_{q} \otimes H_{\tau} \subset\left(H_{-\tau}\right)_{-q} \otimes H_{-\tau}$

$\int f(u) \hat{d} L_{u}$ is not necessary a nonregular test function. Nevertheless, one can introduce on each space of nonregular test functions a linear operator that has properties quite analogous to the properties of the above-mentioned integral. First we note that for $f^{(m)} \in H_{\tau}^{\otimes m} \otimes H_{\tau} \subset H_{-\tau}^{(m)} \otimes H_{-\tau}$ the above-introduced generalized functions : $\left\langle 0^{\otimes m}, f^{(m)}\right\rangle$ : belong to the spaces $\left(H_{\tau}\right)_{q} \otimes H_{\tau}$ and form orthogonal bases in these spaces [13]. So, any $f \in\left(H_{\tau}\right)_{q} \otimes H_{\tau}$ can be presented as

$$
f(\cdot)=\sum_{m=0}^{\infty}:\left\langle 0^{\otimes m}, f^{(m)}\right\rangle:, f^{(m)} \in H_{\tau}^{\otimes ึ} \otimes H_{\tau},
$$

with $\|f\|_{\left(H_{\tau}\right)_{q} \otimes H_{\tau}}^{2}=\sum_{m=0}^{\infty}(m !)^{2} 2^{q m}\left|f^{(m)}\right|_{H_{\tau}^{\otimes m} \otimes H_{\tau}}^{2}<\infty$.

Now we define a linear continuous operator $I:\left(H_{\tau}\right)_{q+1} \otimes H_{\tau} \rightarrow\left(H_{\tau}\right)_{q}$ by setting for $f \in\left(H_{\tau}\right)_{q+1} \otimes H_{\tau}$

of form (11) $I(f):=\sum_{m=0}^{\infty}:\left\langle 0^{\otimes m+1}, \tilde{f}^{(m)}\right\rangle:$, here $\tilde{f}^{(m)}:=\operatorname{Pr} f^{(m)} \in H_{\tau}^{\otimes m+1}, \operatorname{Pr}$ is the orthoprojector 
acting for each $m \in Z_{+}$from $H_{\tau}^{\otimes m} \otimes H_{\tau}$ to $H_{\tau}^{\otimes m+1}$ (the symmetrization operator). The well-posedness of this definition is proved in [13].

Finally, as is well known, an important role in the Lévy white noise analysis belongs to the Hida stochastic derivative, which is the adjoint operator of the extended stochastic integral. In terms of Lytvynov's generalization of the CRP this derivative is considered on $\left(L^{2}\right)$ [2], on the spaces of regular test and generalized functions $[11,12]$ and on the spaces of nonregular test functions $[7,13]$. But, unfortunately, this operator has no a natural extension to the spaces of nonregular generalized functions. Nevertheless, one can define natural analogs of the Hida stochastic derivative on these spaces as operators adjoint to $I$. More exactly, we define a linear continuous operator $\tilde{\partial} .:\left(H_{-\tau}\right)_{-q} \rightarrow\left(H_{-\tau}\right)_{-q-1} \otimes H_{-\tau}$ as the adjoint operator to $I\left(\tilde{\partial}_{.}=I^{*}\right)$, i.e., for all $F \in\left(H_{-\tau}\right)_{-q}$ and $f \in\left(H_{\tau}\right)_{q+1} \otimes H_{\tau} \quad\langle\langle\tilde{\partial} . F, f\rangle\rangle_{\left(L^{2}\right) \otimes H}=\langle\langle F, I(f)\rangle\rangle_{\left(L^{2}\right)}$, here $\langle\langle\cdot, \cdot\rangle\rangle_{\left(L^{2}\right) \otimes H}$ denotes the dual pairing generated by the scalar product in $\left(L^{2}\right) \otimes H$. A simple calculation shows that $\tilde{\partial} . F=\sum_{m=0}^{\infty}(m+1):\left\langle 0^{\otimes m}, F_{\mathrm{ext}}^{(m+1)}(\cdot)\right\rangle:$, here

$$
F_{\mathrm{ext}}^{(m+1)}(\cdot):=\left(U_{m}^{-1} \otimes 1\right)\left[\left(U_{m+1} F_{\mathrm{ext}}^{(m+1)}\right)(\cdot)\right] \in H_{-\tau}^{(m)} \otimes H_{-\tau},
$$

$F_{\mathrm{ext}}^{(m+1)} \in H_{-\tau}^{(m+1)}$ are the kernels from decomposition (6) for $F$.

\section{Operators of stochastic differentiation}

As we said above, the operators of stochastic differentiation on $\left(L^{2}\right)$ [11,12] cannot be naturally continued to the spaces of nonregular generalized functions (because the kernels from decompositions (6) for elements of $\left(H_{-\tau}\right)_{-q}$ belong to the spaces wider than $\left.H_{\mathrm{ext}}^{(m)}\right)$. Nevertheless, one can introduce on these spaces natural analogs of the above-mentioned operators. We begin from a preparation. Let $F_{\mathrm{ext}}^{(m)} \in H_{-\tau}^{(m)}, \quad f^{(n)} \in H_{\tau}^{\otimes n}, \quad n, m \in N$, $m>n$. We define a generalized partial pairing $\left\langle F_{\text {ext }}^{(m)}, f^{(n)}\right\rangle_{\text {ext }} \in H_{-\tau}^{(m-n)}$ by setting for any $g^{(m-n)} \in H_{\tau}^{\widehat{\otimes} m-n}$

$\left\langle\left\langle F_{\mathrm{ext}}^{(m)}, f^{(n)}\right\rangle_{\mathrm{ext}}, g^{(m-n)}\right\rangle_{\mathrm{ext}}=\left\langle F_{\mathrm{ext}}^{(m)}, f^{(n)} \widehat{\otimes} g^{(m-n)}\right\rangle_{\mathrm{ext}}$.
As is easy to verify by the generalized Cauchy-Bunyakovsky inequality, this definition is well-posed and

$$
\left|\left\langle F_{\mathrm{ext}}^{(m)}, f^{(n)}\right\rangle_{\mathrm{ext}}\right|_{H_{-\tau}^{(m-n)}} \leq\left|F_{\mathrm{ext}}^{(m)}\right|_{H_{-\tau}^{(m)}}\left|f^{(n)}\right|_{\tau} .
$$

Definition. Let $f^{(n)} \in H_{\tau}^{\otimes n}, n \in N$. We define the operator of stochastic differentiation $\left(\tilde{D}^{n} \circ\right)\left(f^{(n)}\right)$ : $\left(H_{-\tau}\right)_{-q} \rightarrow\left(H_{-\tau}\right)_{-q-1}$ by the formula

$\left(\tilde{D}^{n} F\right)\left(f^{(n)}\right):=\sum_{m=0}^{\infty} \frac{(m+n) !}{m !}:\left\langle 0^{\otimes m},\left\langle F_{\mathrm{ext}}^{(m+n)}, f^{(n)}\right\rangle_{\mathrm{ext}}\right\rangle:$,

where $F_{\text {ext }}^{(m)} \in H_{-\tau}^{(m)}$ are the kernels from decomposition (6) for $F \in\left(H_{-\tau}\right)_{-q}$. Also we denote $(\tilde{D} \circ)\left(f^{(1)}\right):=\left(\tilde{D}^{1} \circ\right)\left(f^{(1)}\right)$.

By direct calculation with use (7) and (13) one obtains the estimate

$$
\begin{gathered}
\left\|\left(\tilde{D}^{n} F\right)\left(f^{(n)}\right)\right\|_{\left(H_{-\tau}\right)_{-q-1}}^{2} \\
\leq 2^{q n}\left|f^{(n)}\right|_{\tau} \max _{m \in Z_{+}}\left[2^{-m}\left(\frac{(m+n) !}{m !}\right)^{2}\right]\|F\|_{\left(H_{-\tau}\right)_{-q}}^{2},
\end{gathered}
$$

whence it follows that $\left(\tilde{D}^{n} \circ\right)\left(f^{(n)}\right)$ is a welldefined linear continuous (bounded) operator.

Consider properties of $\left(\tilde{D}^{n} \circ\right)\left(f^{(n)}\right)$.

Theorem. 1) For $k_{1}, \ldots, k_{m} \in N, f_{j}^{\left(k_{j}\right)} \in H_{\tau}^{\otimes k_{j}}$, $j \in\{1, \ldots, m\}$

$$
\begin{gathered}
\left(\tilde{D}^{k_{m}}\left(\cdots\left(\tilde{D}^{k_{2}}\left(\left(\tilde{D}^{k_{1}} \circ\right)\left(f_{1}^{\left(k_{1}\right)}\right)\right)\right)\left(f_{2}^{\left(k_{2}\right)}\right) \cdots\right)\right)\left(f_{m}^{\left(k_{m}\right)}\right) \\
=\left(\tilde{D}^{k_{1}+\cdots+k_{m}} \circ\right)\left(f_{1}^{\left(k_{1}\right)} \otimes \cdots \otimes f_{m}^{\left(k_{m}\right)}\right) .
\end{gathered}
$$

2) For each $F \in\left(H_{-\tau}\right)_{-q}$ the kernels $F_{\text {ext }}^{(m)} \in H_{-\tau}^{(m)}$ from decomposition (6) can be presented in a form

$$
F_{\mathrm{ext}}^{(m)}=\frac{1}{m !} E\left(\tilde{D}^{m} F\right),
$$

i.e., for each $f^{(m)} \in H_{\tau}^{\otimes m}$

$$
\left\langle F_{\mathrm{ext}}^{(m)}, f^{(m)}\right\rangle_{\mathrm{ext}}=\frac{1}{m !} E\left(\left(\tilde{D}^{m} F\right)\left(f^{(m)}\right)\right),
$$

here $E_{\circ}:=\langle\langle\circ, 1\rangle\rangle_{\left(L^{2}\right)}$ is a generalized expectation.

3) The adjoin to $\tilde{D}^{n}$ operator has a form

$$
\left(\tilde{D}^{n} g\right)\left(f^{(n)}\right)^{*}=\sum_{m=0}^{\infty}:\left\langle 0^{\otimes m+n}, g^{(m)} \widehat{\otimes} f^{(n)}\right\rangle: \in\left(H_{\tau}\right)_{q},
$$


where $g \in\left(H_{\tau}\right)_{q+1}, \quad f^{(n)} \in H_{\tau}^{\otimes n}$, and $g^{(m)} \in H_{\tau}^{\otimes m}$ are the kernels from decomposition (3) for $g$.

4) For all $g \in\left(H_{\tau}\right)_{q+1}$ and $f^{(1)} \in H_{\tau}$

$$
(\tilde{D} g)\left(f^{(1)}\right)^{*}=I\left(g \otimes f^{(1)}\right) \in\left(H_{\tau}\right)_{q} .
$$

5) For all $F \in\left(H_{-\tau}\right)_{-q}$ and $f^{(1)} \in H_{\tau}$ we have

$$
(\tilde{D} F)\left(f^{(1)}\right)=\left\langle\tilde{\partial} . F, f^{(1)}(\cdot)\right\rangle \in\left(H_{-\tau}\right)_{-q-1},
$$

where $\left\langle\tilde{\partial} F, f^{(1)}(\cdot)\right\rangle$ is a partial pairing, i.e., the unique element of $\left(H_{-\tau}\right)_{-q-1}$ such that for arbitrary

$$
\begin{aligned}
g & \in\left(H_{\tau}\right)_{q+1} \\
& \left\langle\left\langle\left\langle\tilde{\partial} . F, f^{(1)}(\cdot)\right\rangle, g\right\rangle\right\rangle_{\left(L^{2}\right)}=\left\langle\left\langle\tilde{\partial} . F, g \otimes f^{(1)}(\cdot)\right\rangle\right\rangle_{\left(L^{2}\right) \otimes H} .
\end{aligned}
$$

Formally $\tilde{\partial}_{.} \circ=(\tilde{D} \circ)(\delta$. $)$, where $\delta$. is the Dirac delta-function.

$$
\begin{aligned}
& \text { 6) Let } F \in\left(H_{-\tau}\right)_{-q} \otimes H_{-\tau}, f^{(1)} \in H_{\tau} \text {. Then } \\
& \left(\tilde{D} \int F(u) \hat{d} L_{u}\right)\left(f^{(1)}\right) \\
& =\int(\tilde{D} F(u))\left(f^{(1)}\right) \hat{d} L_{u}+\left\langle F(\cdot), f^{(1)}(\cdot)\right\rangle \in\left(H_{-\tau}\right)_{-q-1},
\end{aligned}
$$

here $\left\langle F(\cdot), f^{(1)}(\cdot)\right\rangle$ is a partial pairing.

Proof. 1) The application of the mathematical induction method.
2) The direct calculation with use (14) and (8).

3) The direct calculation with use (14), (3), (12), (8) and (6). of $I$.

4) The consequence of (15) and the definition

5) The direct calculation with use (16) and the definition of $\tilde{\partial}$.

6) The direct calculation with use (14), the definition of the extended stochastic integral, (12) and (8). $\square$

\section{Conclusions}

In this paper the operators of stochastic differentiation are considered on the spaces of nonregular generalized functions of the Lévy white noise analysis; and some properties of these operators are established. This can be interpreted as a contribution in a further development of the Lévy analysis. In particular, using the introduced operators one can study some properties of the extended stochastic integral and of solutions of socalled normally ordered stochastic equations. In forthcoming papers we'll consider elements of the Wick calculus on the spaces of nonregular test and generalized functions, the connection between the Wick calculus and the stochastic differentiation and integration, etc.

\section{List of the literature}

1. Bertoin J. Lévy Processes. - Cambridge: Cambridge University Press, 1996. - X+265 p.

2. Kachanovsky N.A. On extended stochastic integrals with respect to Lévy processes // Carpatian Math. Publ. - 2013. - 5, № 2. P. 256-278.

3. Lytvynov E.W. Orthogonal decompositions for Lévy processes with an application to the gamma, Pascal, and Meixner processes // Infin. Dimens. Anal. Quantum Probab. Relat. Top. - 2003. - 6, № 1. - P. 73-102.

4. Itô $K$. Spectral type of the shift transformation of differential processes with stationary increments // Trans. Am. Math. Soc. 1956. - 81. - P. 253-263.

5. Di Nunno G., Oksendal B., Proske F. White noise analysis for Lévy processes // J. Funct. Anal. - 2004. - 206, № 1. - P. $109-148$.

6. Di Nunno G., Oksendal B., Proske F. Malliavin Calculus for Lévy Processes with Applications to Finance. - Berlin, Heidelberg: Universitext, Springer-Verlag, 2009. - XIII+417 p.

7. Kachanovsky N.A. Extended stochastic integrals with respect to a Lévy process on spaces of generalized functions // Math. Bull. Taras Shevchenko Sci. Soc. - 2013. - 10. - P. 169-188.

8. Dyriv M.M., Kachanovsky N.A. Stochastic integrals with respect to a Lévy processes and stochastic derivatives on spaces of regular test and generalized functions // Naukovi Visti NTUU “KPI". - 2013. - № 4. - P. 27-30.

9. Ustunel A.S. An Introduction to Analysis on Wiener Space. - Berlin, Heidelberg: Lecture Notes in Math., 1610, SpringerVerlag, 1995. $-\mathrm{X}+106 \mathrm{p}$.

10. Benth F.E. The Gross derivative of generalized random variables // Infin. Dimens. Anal. Quantum Probab. Relat. Top. 1999. - 2, № 3. - P. 381-396.

11. Dyriv M.M., Kachanovsky N.A. Operators of stochastic differentiation on spaces of regular test and generalized functions in the Lévy white noise analysis // Naukovi Visti NTUU “KPI”. - 2014. - 81, № 4. - P. 36-40.

12. Dyriv M.M., Kachanovsky N.A. On operators of stochastic differentiation on spaces of regular test and generalized functions of Lévy white noise analysis // Carpatian Math. Publ. - 2014. - 6, № 2. - P. 212-229. 
13. Kachanovsky N.A. Operators of stochastic differentiation on spaces of nonregular test functions of Lévy white noise analysis // Methods Funct. Anal. Topol. - 2015. - 21, № 4. - P. 336-360.

14. Berezansky Yu.M., Sheftel Z.G., Us G.F. Functional Analysis. Vol. 2. - Basel, Boston, Berlin: Birkhauser, 1996. - XVII+312 p.

15. Kachanovsky N.A. On an extended stochastic integral and the Wick calculus on the connected with the generalized Meixner measure Kondratiev-type spaces // Methods Funct. Anal. Topol. - 2007. - 13, № 4. - P. 338-379.

\section{References}

1. J. Bertoin, Lévy Processes. Cambridge, GB: Cambridge University Press, 1996, p. X+265.

2. N.A. Kachanovsky, "On extended stochastic integrals with respect to Lévy processes", Carpatian Math. Publ., vol. 5, no. 2, pp. 256-278, 2013.

3. E.W. Lytvynov, "Orthogonal decompositions for Lévy processes with an application to the gamma, Pascal, and Meixner processes”, Infin. Dimens. Anal. Quantum Probab. Relat. Top., vol. 6, no. 1, pp. 73-102, 2003.

4. K. Itô, "Spectral type of the shift transformation of differential processes with stationary increments", Trans. Am. Math. Soc., vol. 81 , pp. 253-263, 1956.

5. G. Di Nunno et al., "White noise analysis for Lévy processes”, J. Funct. Anal., vol. 206, no. 1, pp. 109-148, 2004.

6. G. Di Nunno et al., Malliavin Calculus for Lévy Processes with Applications to Finance. Berlin, Heidelberg, Germany: Universitext, Springer-Verlag, 2009, p. XIII+417.

7. N.A. Kachanovsky, "Extended stochastic integrals with respect to a Lévy process on spaces of generalized functions", Math. Bull. Taras Shevchenko Sci. Soc., vol. 10, pp. 169-188, 2013.

8. M.M. Dyriv and N.A. Kachanovsky, "Stochastic integrals with respect to a Lévy processes and stochastic derivatives on spaces of regular test and generalized functions", Naukovi Visti NTUU “KPI”, no. 4, pp. 27-30, 2013.

9. A.S. Ustunel, An Introduction to Analysis on Wiener Space. Berlin, Heidelberg, Germany: Lecture Notes in Math., 1610, Springer-Verlag., 1995, p. X+106.

10. F.E. Benth, "The Gross derivative of generalized random variables", Infin. Dimens. Anal. Quantum Probab. Relat. Top., vol. 2, no. 3, pp. 381-396, 1999.

11. M.M. Dyriv and N.A. Kachanovsky, "Operators of stochastic differentiation on spaces of regular test and generalized functions in the Lévy white noise analysis", Naukovi Visti NTUU "KPI”, no. 4, pp. 36-40, 2014.

12. M.M. Dyriv and N.A. Kachanovsky, "On operators of stochastic differentiation on spaces of regular test and generalized functions of Lévy white noise analysis", Carpatian Math. Publ., vol. 6, no. 2, pp. 212-229, 2014.

13. N.A. Kachanovsky, "Operators of stochastic differentiation on spaces of nonregular test functions of Lévy white noise analysis”, Methods Funct. Anal. Topol., vol. 21, no. 4, pp. 336-360, 2015.

14. Yu.M. Berezansky et al., Functional Analysis, vol. 2. Basel, Boston, Berlin: Birkhauser, 1996, p. XVII+312.

15. N.A. Kachanovsky, "On an extended stochastic integral and the Wick calculus on the connected with the generalized Meixner measure Kondratiev-type spaces”, Methods Funct. Anal. Topol., vol. 13, no. 4, pp. 338-379, 2007.

М.О. Качановський

\section{ОБМЕЖЕНІ ОПЕРАТОРИ СТОХАСТИЧНОГО ДИФЕРЕНЦІЮВАННЯ НА ПРОСТОРАХ НЕРЕГУЛЯРНИХ УЗАГАЛЬНЕНИХ} ФУНКЦІЙ В АНАЛІЗІ БІЛОГО ШУМУ ЛЕВІ

Проблематика. Оператори стохастичного диференціювання грають важливу роль у гауссовому аналізі білого шуму. Зокрема, вони можуть використовуватись для вивчення властивостей розширеного стохастичного інтеграла та розв'язків нормально впорядкованих стохастичних рівнянь. Хоч гауссів аналіз є розвинутою теорією з численними застосуваннями, у математичних задачах виникають не лише гауссові випадкові процеси. Зокрема, важлива роль у сучасних дослідженнях належить процесам Леві. Тому необхідно розбудовувати аналіз Леві, включаючи теорію операторів стохастичного диференціювання.

Мета дослідження. Протягом останніх років оператори стохастичного диференціювання були уведені та вивчені, зокрема, на просторах регулярних основних і узагальнених функцій та на просторах нерегулярних основних фрункцій аналізу Леві. У цій статті ми робимо наступний крок: уводимо та вивчаємо такі оператори на просторах нерегулярних узагальнених функцій.

Методика реалізації. Ми використовуємо, зокрема, теорію гільбертових оснащень та литвинівське узагальнення властивості хаотичного розкладу.

Результати досліджень. Основним результатом є теорема про властивості операторів стохастичного диференціювання.

Висновки. Оператори стохастичного диференціювання розглянуто на просторах нерегулярних узагальнених функцій аналізу білого шуму Леві. Це можна розуміти як внесок у подальший розвиток аналізу Леві. Застосування введених операторів $\epsilon$ цілком аналогічними застосуванням відповідних операторів у гауссовому аналізі.

Ключові слова: оператор стохастичного диференціювання; розширений стохастичний інтеграл; стохастична похідна Хiди; процес Леві. 
Н.А. Качановский

ОГРАНИЧЕННЫЕ ОПЕРАТОРЫ СТОХАСТИЧЕСКОГО ДИФФЕРЕНЦИРОВАНИЯ НА ПРОСТРАНСТВАХ НЕРЕГУЛЯРНЫХ ОБОБЩЕННЫХ ФУНКЦИЙ В АНАЛИЗЕ БЕЛОГО ШУМА ЛЕВИ

Проблематика. Операторы стохастического дифференцирования играют важную роль в гауссовском анализе белого шума. В частности, эти операторы можно использовать для изучения свойств расширенного стохастического интеграла и решений нормально упорядоченных стохастических уравнений. Хотя гауссовский анализ - это развитая теория с многочисленными приложениями, в математических задачах появляются не только гауссовские случайные процессы. В частности, важная роль в современных исследованиях принадлежит процессам Леви. Поэтому необходимо развивать анализ Леви, включая теорию операторов стохастического дифференцирования.

Цель исследования. В последние годы операторы стохастического дифференцирования были введены и изучены, в частности, на пространствах регулярных основных и обобщенных функций и на пространствах нерегулярных основных функций анализа Леви. В этой статье мы делаем следующий шаг: вводим и изучаем такие операторы на пространствах нерегулярных обобщенных функций.

Методика реализации. Мы используем, в частности, теорию гильбертовых оснащений и литвиновское обобщение свойства хаотического разложения.

Результаты исследования. Основной результат - теорема о свойствах операторов стохастического дифференцирования.

Выводы. Операторы стохастического дифференцирования рассмотрены на пространствах нерегулярных обобщенных функций анализа белого шума Леви. Это можно понимать как вклад в дальнейшее развитие анализа Леви. Применения введенных операторов вполне аналогичны применениям соответствующих операторов в гауссовском анализе.

Ключевые слова: оператор стохастического дифференцирования; расширенный стохастический интеграл; стохастическая производная Хиды; процесс Леви.

Рекомендована Радою

фізико-математичного факультету

НТУУ "КПІ"
Надійшла до редакції

18 грудня 2015 року 